\title{
Phase-Lag Compensator based Approach for Realizing MPPT through PMSG based Wind Turbine Generator
}

\author{
Puneet Kumar Srivastava \\ Department of Electrical Engineering, \\ Madan Mohan Malaviya University of Technology, Gorakhpur, Uttar Pradesh, India. \\ Corresponding author: puneetsrivastava_rsee@mmmut.ac.in \\ Amar Nath Tiwari \\ Department of Electrical Engineering, \\ Madan Mohan Malaviya University of Technology, Gorakhpur, Uttar Pradesh, India. \\ E-mail: antee@mmmut.ac.in \\ Sri Niwas Singh \\ Department of Electrical Engineering, \\ Madan Mohan Malaviya University of Technology, Gorakhpur, Uttar Pradesh, India. \\ E-mail: snsingh@iitk.ac.in
}

(Received June 25, 2020; Accepted December 2, 2020)

\begin{abstract}
Proportional-Integral (PI) controllers are widely accepted industrial controllers. These controllers also find their applications in wind energy conversion systems (WECSs). Although such controllers are well researched and developed too, their linear nature and sensitivity of their gains towards variations in plant's parameter are some noticeable disadvantages associated with them. Moreover, tuning of their gains involves certain approximations, which leads to demean their accuracy. On contrary, the designing of lag-compensators is procedural and discussed well in literature. Although such compensators could not have drawn the attention of wind turbine manufacturers but may a potential candidate for future developments. The focus of this paper is to design phase-lag compensators and use them to extract maximum available power in the wind, at every wind speed upto its rated value. Ability of the compensators is assessed through detailed simulation of a PMSG based WECS in MATLAB/Simulink environment. Observed responses are motivating and demonstrates the effectiveness of the designed compensators.
\end{abstract}

Keywords- Controller Design, Lag Compensator, Rotor-Field-Oriented-Control (R-FOC), Tip-Speed-Ratio (TSR), Maximum Power Point Tracking (MPPT).

\section{Introduction}

Amongst various wind turbine generators (WTGs), the permanent magnet synchronous generator (PMSG) based WTGs are most popular in variable speed wind turbines (VSWTs). VSWTs also uses doubly fed inducton generator (DFIG), however, PMSG based WTGs are more advantageous over DFIG based WTGs. Most of the modern WTGs are PMSG based owing to its several advantages such as gearless design, self-excitation capability, higher efficiency, improved reliability, and less maintenance (Sharma and Singh, 2012; Yaramasu et al., 2017). The most lucrative feature of PMSG based WTGs is its wide operating speed range and fully utilization of the converter's capacity (Chinchilla et al., 2006; Polinder et al., 2006). In general, the major challenge associated with wind energy generation is WTG's integration with the grid (Dahbi et al., 2014; Mohseni and Islam, 2012). Due to intermittency in the wind the power generated from such sources are inconsistent, and affects the system's stability and power quality. In order to address these, power electronic interfaces are required for bridging such sources with the grid, 
International Journal of Mathematical, Engineering and Management Sciences

Vol. 6, No. 2, 584-597, 2021

https://doi.org/10.33889/IJMEMS.2021.6.2.035

which needs to be properly controlled, so as to obtain optimum generation along with fulfilling the grid code requirements in terms of voltage, frequency, active and reactive power injection (Freire et al., 2012; Jain et al., 2015; Tripathi et al., 2015).

Various power electronic interfaces proposed for bridging the PMSG based WTGs with the grid are reviewed in past, and back-to-back connected pulse-width-modulated voltage-sourceconverters (BTB-PWM-VSCs) are unanimously accepted, and hence are most preffered interfaceing option (Baroudi et al., 2007; Yaramasu et al., 2015). In BTB-PWM-VSCs, the VSCs are usually termed as mashine-side-converter (MSC) and grid-side-converter (GSC) based on their location. Field-Oriented-Control (FOC) and direct-torque-control (DTC) are used to control the MSC, whereas, voltage-oriented-control (VOC) and direct-power-control (DPC) are used to control GSC. Amoung these, FOC and VOC are vector based conrol approaches, whereas, DTC and DPC are direct control approaches. A comparative analysis of PMSG drives with direct and vector based control is presented in (Freire et al., 2012). The vector based control approaches are highly researched and established in view of their better performance in terms of current distortions, power factor, and efficiency (Jain et al., 2015; Tiwari and Babu, 2016). FOC and VOC are of cascaded structure, and consists of a faster inner-current-control loop and a slower outer-speed/voltage-control loop (Dahbi et al., 2014; Jain et al., 2015). Propper control of MSC and GSC is imperative for achieving desired performance and system's stability, which needs the involve controllers to meet certain design specifications, such as; percentage overshoot; rise time; settling time; phase margin; and specified bandwidth (Basilio and Matos, 2002; Kristiansson and Lennartson, 2006; Li, 2012). Simple structure, cost-effectiveness and simple designing procedure makes the PI controllers as most preffered controller option for industrial drives. In view of aforementioned attributes such controllers also has dragged WT manufacturer's attension. PI controller design/tuning requires computation of proportional and integral gains and number of tuning procedures are proposed in literature (Krohling and Rey, 2001; Neath et al., 2014; Zigmund et al., 2011).

As the idea of compensation seems lucrative as compared to control. In view of this, the focus of present study is on designing of lag compensators to control the speed of PMSG based WTGs. Besides noticeable benifits of lag-compensators over PI controllers very few studies are found on its use in WECS control. One such work is reported in Wang et al. (2009), in which autors have used phase-lag compensator to enhance the low-voltage-ride-through (LVRT) capability of a doubly-fed-induction-generator (DFIG) based wind energy conversion system. In another work reported in Hamatwi et al. (2017), authors have presented a detailed lag-compensator design procedure for MSC control of a PMSG based WECS, in which they have directly controlled the generated power to achieve MPPT. As large current involves in power control, it should be avoided for megawatt capacity WTGs. This paper focuses on designing of phase-lag compensators for both inner and outer control loops of the MSC control to achive MPPT. The inner and outer control loops are used to control the current and speed, respectively.

\section{PMSG based WTG}

PMSG's stator voltage equations in rotating reference frame, electromagnetic torque relation, and rotor dynamics are expressed as (Wu et al., 2011),

$$
v_{d s}=R_{s} i_{d s}+L_{d s} \frac{d}{d t} i_{d s}-\omega_{r} L_{d s} i_{q s}
$$


$v_{q s}=R_{s} i_{q s}+L_{q s} \frac{d}{d t} i_{q s}+\omega_{r} L_{q s} i_{d s}+\omega_{r} \psi_{r}$

$T_{e m}=\frac{3}{2}\left(\frac{P}{2}\right) \cdot\left[\psi_{d s} i_{q s}+\left(L_{d s}-L_{q s}\right) i_{d s} i_{q s}\right]$

$J \frac{d}{d t} \omega_{m e}=T_{m e}-T_{e m}$

where, $v$ is voltage, $i$ is current, $R$ is resistance, $L$ is inductance, $\omega_{r}$ is rotor's electrical angular speed, $\omega_{m e}$ is turbines mechanical angular speed, $P$ is number of PMSG poles, $\psi$ is PMSG's rotor field flux, $J$ is combined inertia of turbine-generator system, $T_{m e}$ is mechanical torque of the turbibe, and $T_{e m}$ is PMSG's electromagnetic torque. Subscripts $\mathrm{d}$ and q denotes direct and quadrature axis quantities, respectively, whereas, subscript s indicates stator quantities. Further, in the present study, a surface mounted PMSG has used, therefore the reluctance torque produced by transformed inuctances reduces to zero and Eqn. (3) can be rewritten as,

$$
T_{e m}=\frac{3}{2}\left(\frac{P}{2}\right) \psi_{d s} i_{q s}
$$

\section{Machine Side Converter Control}

Usually, MSC control, controls the generator's speed in order to maintain the tip-speed-ratio (TSR) at it's optimum value. It enables the WT to operate in constant $\mathrm{Cp}$ mode and hence to achieve the MPPT. The control philosophy of MSC control has already discussed in various publications in the past (Freire et al., 2012; Jain et al., 2015). Field-oriented-control (FOC) techniques are highly researched and accepted control technique for MSC control. Amongst various FOC techneques, such as, stator-field-oriented-control (SFOC); rotor-field-orientedcontrol (RFOC) and Airgap-field-oriented-control (AGFOC), the RFOC is most popular control scheme for controlling the MSC of PMSG based WECSs. In present work RFOC scheme is used. The scheme is well discussed in Wu et al. (2011).

\subsection{Compensator Design Specifications}

The ripple content in the converter's output may badly affect the compensator's performance. In order to avoid this, the compensator's bandwidth must be chosen high. The converter switching frequency has considered $10 \mathrm{kHz}$ in present study. Compensator bandwidths for inner and outer control loops are considered $2 \mathrm{kHz}$ and $0.5 \mathrm{kHz}$, respectively. In addition, the maximum overshoot allowed is considered 20\% for inner and 5\% for outer control loop in view of their faster and slower response. Other compensator design parameters are computed and are presented in Table 1 (Ogata and Yang, 2002). 
International Journal of Mathematical, Engineering and Management Sciences

Vol. 6, No. 2, 584-597, 2021

https://doi.org/10.33889/IJMEMS.2021.6.2.035

Table 1. Compensators design specifications.

\begin{tabular}{|c|c|c|}
\hline Machine Side Converter Control & $\begin{array}{l}\text { Inner Current } \\
\text { Control (ICC) Loop }\end{array}$ & $\begin{array}{l}\text { Outer Speed } \\
\text { Control (OSC )Loop }\end{array}$ \\
\hline Design Parameters & Values & Values \\
\hline Desired Bandwidth $\omega_{d}$ & $2 \mathrm{kHz}(12566.37 \mathrm{rad} / \mathrm{s})$ & $500 \mathrm{~Hz}(3141.59 \mathrm{rad} / \mathrm{s})$ \\
\hline Maximum Overshoot $M_{p}$ & $20 \%$ & 0.690 \\
\hline Damping Ratio $\zeta$ & 0.456 & $64.62^{0}$ \\
\hline Phase Margin $P M$ & $48.15^{0}$ & $3067.42 \mathrm{rad} / \mathrm{s}$ \\
\hline Natural Frequency $\omega_{n}$ & $9520.43 \mathrm{rad} / \mathrm{s}$ & $0.683 \mathrm{~ms}$ \\
\hline Rise Time $T_{r}$ & $0.163 \mathrm{~ms}$ & $1.889 \mathrm{~s}$ \\
\hline Settling Time $T_{s}$ & $0.921 \mathrm{~ms}$ & \\
\hline
\end{tabular}

\subsection{Open Loop Transfer Function: ICC loop of MSC}

Block diagram of the ICC loop of MSC control is shown in Figure 1.

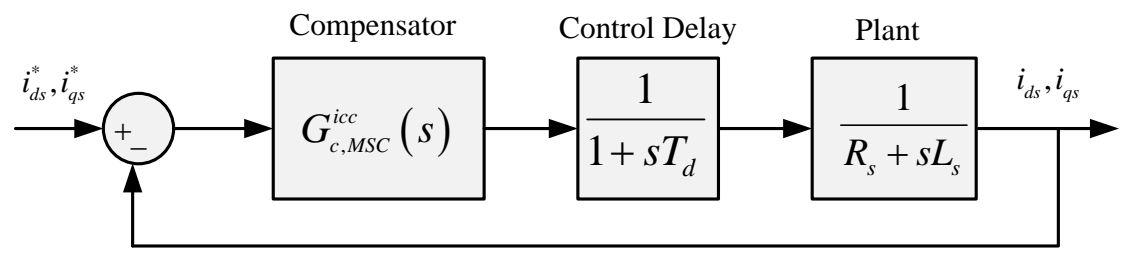

Figure 1. Block diagram of the ICC loop of MSC control.

The plant's transfer function of the ICC loop relating the $d q$-axis components of the stator current to the $d q$-axis components of stator voltage is approximated as (Kim et al., 2012),

$$
\left[\begin{array}{ll}
\frac{i_{d s}(s)}{u_{d s}^{*}(s)} & \frac{i_{q s}(s)}{u_{q s}^{*}(s)}
\end{array}\right]^{T}=\left[\begin{array}{ll}
\frac{1}{R_{s}+s L_{d s}} & \frac{1}{R_{s}+s L_{q s}}
\end{array}\right]^{T}
$$

Now, the converter transfer function $\mathrm{G}_{\text {conv }}(\mathrm{s})$ is represented as first-order transfer function with a delay $T_{d}$ (Tripathi et al., 2016). The transfer function of the converter block is expressed as,

$$
G_{c o n v}(s)=\frac{1}{1+s T_{d}}
$$

Therefore, the open-loop-transfer-function (OLTF) of the ICC loop of MSC control $G_{i c c, M S C}^{o l}$ is obtained as,

$$
G_{i c c, M S C}^{o l}(s)=G_{c, M S C}^{i c c}(s)\left(\frac{1}{1+s T_{d}}\right)\left(\frac{1}{R_{s}+s L_{s}}\right)
$$

where, $G_{c, M S C}^{i c c}(s)$ is compensator's transfer function. 
International Journal of Mathematical, Engineering and Management Sciences

Vol. 6, No. 2, 584-597, 2021

https://doi.org/10.33889/IJMEMS.2021.6.2.035

\subsubsection{Compensator Designing for ICC Loop}

Designing process initiates with the response of uncompensated system, for which the OLTF of the uncompensated ICC loop $G_{i c c, M S C}^{o l, u c}(s)$ is obtained using (8) and is given as,

$$
G_{i c c, M S C}^{o l, u c}(s)=\frac{1}{7.865 \times 10^{-8} \mathrm{~s}^{2}+0.001573 \mathrm{~s}+0.000821}
$$

The phase-margin (PM) and bandwidth (BW) from the frequency response of the uncompensated system has found as $88.2^{\circ}$ and $635 \mathrm{rad} / \mathrm{s}$, respectively. Obtained value of PM is high enough and indicates high robustness, whereas, obtained BW is far below to the desired and indicates slower response of uncompensated system. In order to obtain the required $\mathrm{BW}$, the magnitude plot needs upward shifting, so that it may cross the $0 \mathrm{~dB}$ axis at the desired BW or gain crossover frequency. This has achieved by including a gain ' $\mathrm{K}$ '. The desired gain ' $\mathrm{K}$ ' has obtained as 23.34 , and the OLTF of gain-compensated system $G_{i c c, M S C}^{o l, g c}(s)$ is expressed as,

$$
G_{i c c, M S C}^{o l, g c}(s)=\frac{23.34}{7.865 \times 10^{-8} \mathrm{~s}^{2}+0.001573 \mathrm{~s}+0.000821}
$$

The PM and BW obtained from the frequency response of the gain-compensated system are as $57.9^{0}$ and $1.26^{*} 10^{4} \mathrm{rad} / \mathrm{s}$, respectively. With this, BW requirement is met but the PM is more than the desired. Figure 2 presents the magnitude and phase plots for both uncompensated and gaincompensated systems. Magnitude curve shifting and BW adjustment is clearly demonstrated in Figure 2, itself. Futher, in order to achive the desired PM, the gain compensated system is augmented with a phase-lag compensator. Designing of lag-compensator is presented in subsection to be followed.

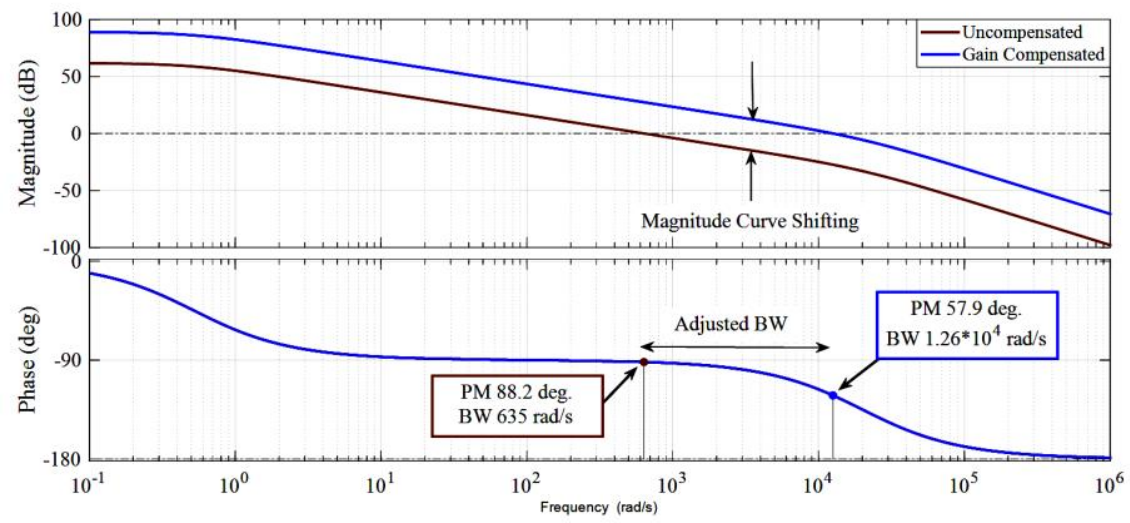

Figure 2. Bode diagram of uncompensated and gain-compensated OLTF of ICC-MSC.

\subsubsection{Phase-Lag Compensator Design}

Phase-lag cpmensator designing requires computation of the amount of phase to be compensated/attenuated, edge frequencies corresponding to location of compensator's pole and zero, compensator's gain and lag time-constant. Numarical values of aforementioned quantities has computed and are presented in Table 2. For the relations used to compute these parameters readers are suggested to refer Ogata and Yang (2002). 
International Journal of Mathematical, Engineering and Management Sciences

Vol. 6, No. 2, 584-597, 2021

https://doi.org/10.33889/IJMEMS.2021.6.2.035

Transsfer function of the phase-lag compensator for ICC loop of the MSC control $G_{\text {lag.i }}(s)$ has obtained and expressed as,

$G_{\text {lag. } . i}(s)=G_{c o}\left(\frac{s T_{\text {lag }}+1}{s \alpha T_{\text {lag }}+1}\right)=1.1866\left(\frac{0.067 \times 10^{-3} \mathrm{~s}+1}{0.09443 \times 10^{-3} \mathrm{~s}+1}\right)$

Now, the OLTF of gain-lag compensated ICC loop of the MSC control $G_{i c c, M S C}^{o l, g l c}(s)$ is obtained as,

$G_{i c c, M S C}^{g l c}(s)=\frac{0.001858 \mathrm{~s}+27.7}{7.427 \times 10^{-12} \mathrm{~s}^{3}+2.272 \times 10^{-7} \mathrm{~s}^{2}+0.001573 \mathrm{~s}+0.000821}$

Table 2. Design aarameters for lag-compensator (ICC-loop).

\begin{tabular}{|c|c|c|}
\hline Parameters & Description & Value \\
\hline$\Delta \phi_{c}$ & Phase Attenuation Required & $-9.75^{\circ}$, \\
\hline$\omega_{p}$ & $\begin{array}{c}\text { Bandwidth Corresponding to the Location } \\
\text { of Compensator's Pole }\end{array}$ & $10591.24 \mathrm{rad} / \mathrm{s}$ \\
\hline$\omega_{z}$ & $\begin{array}{c}\text { Bandwidth Corresponding to the Location } \\
\text { of Compensator's Zero }\end{array}$ & $14909.83 \mathrm{rad} / \mathrm{s}$ \\
\hline$\alpha$ & Constant Representing Ratio of $\omega_{z} \& \omega_{p}$ & 1.408 \\
\hline$G_{c o}$ & Compensator's Gain & $0.067 \times 10^{-3}$ \\
\hline$T_{\text {lag }}$ & Compensator's Time-Constant & 0 \\
\hline
\end{tabular}

The PM and BW obtained from the bode diagram of gain-lag compensated system are as $48.1^{0}$ and $1.26^{*} 10^{4} \mathrm{rad} / \mathrm{s}$, respectively. Therefore, both PM and BW requirement are met. Actually, the phase-lag compensator shifts the phase curve down corresponding to the desired attenuation (around the desired BW). Bode diagram of both gain-compensated and gain-lag compensated systems are shown in Figure 3.

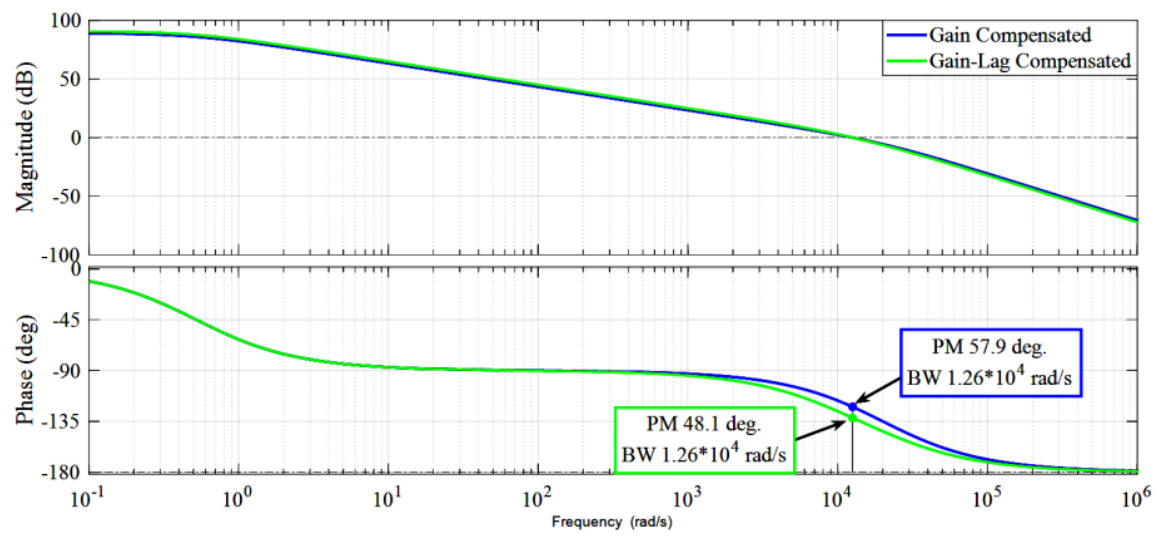

Figure 3. Bode diagram of gain compensated and gain-lag compensated OLTF of ICC-MSC. 
In order to observe the time-response of the system, step-responses of uncompensated, gain compensated and gain-lag compensated systems are obtained and system's performance parameters such as; maximum overshoot, rise time and settling time are noted. Figure 4, shows these responses along with different performance indices.

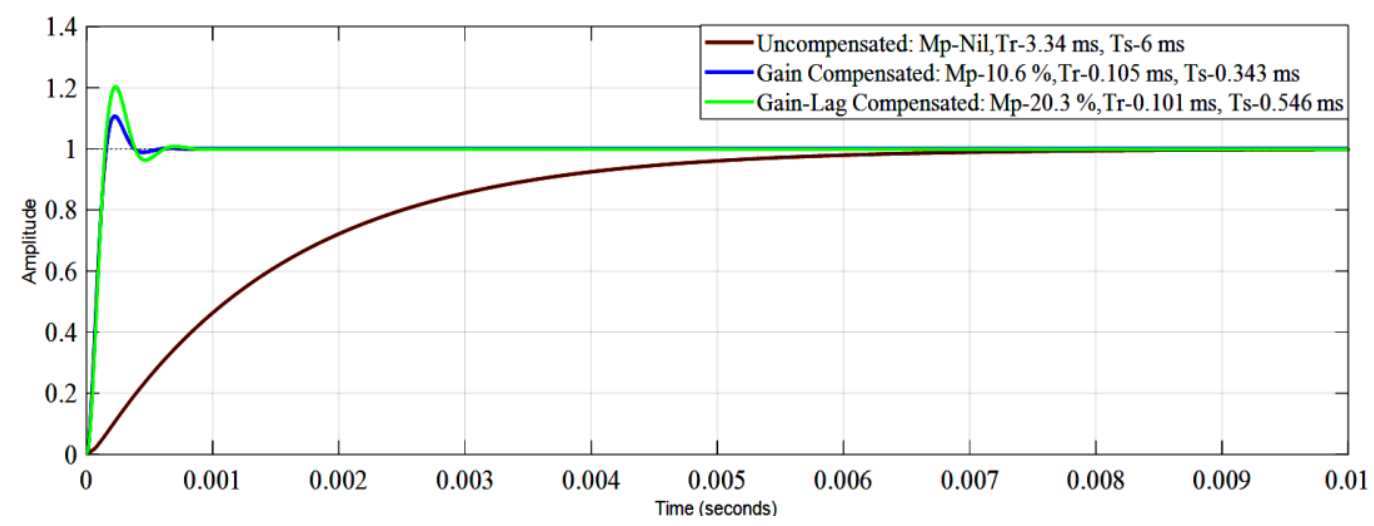

Figure 4. Time response of uncompensated, gain-compensated and gain-lag compensated systems.

\subsection{Open Loop Transfer Function: OSC loop of MSC}

Block diagram of the OSC loop of MSC control is shown in Figure 5.

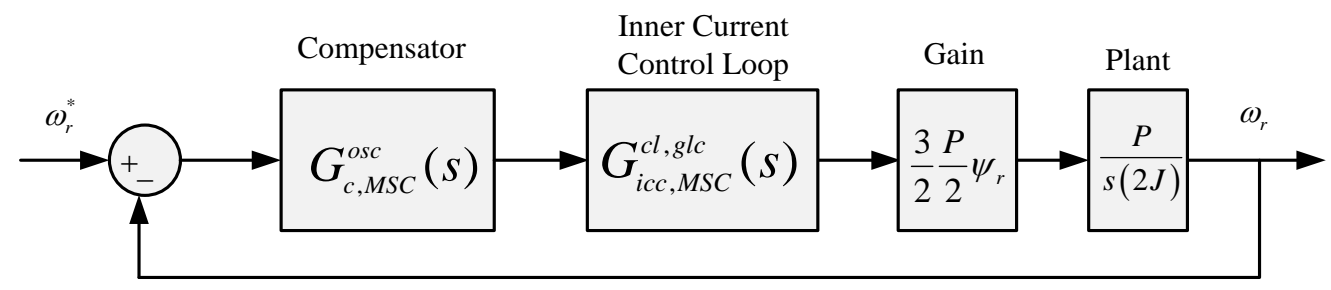

Figure 5. Block diagram of the OSC loop of MSC control.

The plant's transfer function of the OSC loop, relating electrical speed of the rotor and quadrature axis component of stator current is expressed as (Wu et al., 2011),

$$
G_{p l}(s)=\frac{\omega_{r}(s)}{i_{q s}(s)}=\left(\frac{P}{2 J s}\right)
$$

Therefore, the OLTF of the OSC loop of MSC control $G_{o s c, M S C}^{o l}(s)$ is obtained as,

$$
G_{o s c, M S C}^{o l}(s)=G_{c, M S C}^{o s c}(s) \times G_{i c c, M S C}^{c l, g l c}(s) \times \frac{3}{2} \frac{P}{2} \psi_{d s} \times \frac{P}{s 2 J}
$$

where, $G_{c, M S C}^{o s c}(s)$ is compensator's transfer function and $G_{i c c, M S C}^{c l, g l c}(s)$ is closed-loop-transferfunction (CLTF) of gain-lag compensated ICC loop of the MSC. 
International Journal of Mathematical, Engineering and Management Sciences

Vol. 6, No. 2, 584-597, 2021

https://doi.org/10.33889/IJMEMS.2021.6.2.035

\subsubsection{Compensator Designing for OSC Loop}

Designing process initiates with the response of uncompensated system, for which the OLTF of the OSC loop $G_{o s c, M S C}^{o l, u c}(s)$ is obtained using (14) and is given as,

$$
G_{o s c, M S C}^{o l, u c}(s)=\frac{0.001552 \mathrm{~s}+23.14}{7.427 \times 10^{-12} \mathrm{~s}^{4}+2.272 \times 10^{-7} \mathrm{~s}^{3}+0.003431 \mathrm{~s}^{2}+27.7 \mathrm{~s}}
$$

The PM and BW from the frequency response of the uncompensated system has found as $90^{\circ}$ and $0.835 \mathrm{rad} / \mathrm{s}$, respectively. Obtained value of PM is very high indicating high robustness, whereas, obtained BW is far below to the desired and indicates slower response of uncompensated system. In order to obtain the required BW, the magnitude plot needs upward shifting, so that it may cross the $0 \mathrm{~dB}$ axis at the desired BW or gain crossover frequency. This has achieved by including a gain ' $\mathrm{K}$ '. The desired gain ' $\mathrm{K}$ ' has obtained as 3660 , and the OLTF of gain-compensated system $G_{o s c, M S C}^{o l, g c}(s)$ is expressed as,

$$
G_{o s c, M S C}^{o l, g c}(s)=\frac{5.68 \mathrm{~s}+8.469 \mathrm{e} 04}{7.427 \times 10^{-12} \mathrm{~s}^{4}+2.272 \times 10^{-7} \mathrm{~s}^{3}+0.003431 \mathrm{~s}^{2}+27.7 \mathrm{~s}}
$$

The PM and BW obtained from the frequency response of the gain-compensated system are as $79.4^{0}$ and $3.14^{*} 10^{3} \mathrm{rad} / \mathrm{s}$, respectively. With this, BW requirement is met but the PM is more than the desired. Figure 6, presents the magnitude and phase plots for both uncompensated and gaincompensated systems. Futher, in order to achive the desired PM, the gain compensated system is augmented with a phase-lag compensator. Designing of lag-compensator is presented in subsection to be followed.

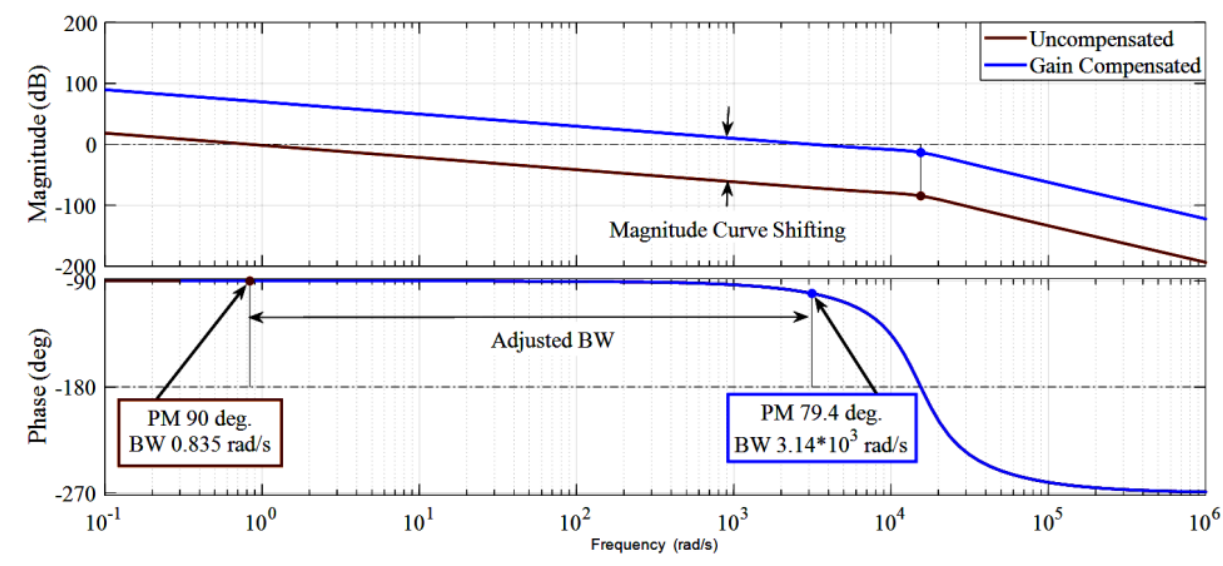

Figure 6. Bode diagram of uncompensated and gain-compensated OLTF of OSC-MSC.

\subsubsection{Phase-Lag Compensator Design}

Numarical values of various design parameters for phase-lag compensator has computed and are presented in Table 3. 
International Journal of Mathematical, Engineering and Management Sciences

Vol. 6, No. 2, 584-597, 2021

https://doi.org/10.33889/IJMEMS.2021.6.2.035

Table 3. Design parameters for lag-compensator (OSC-loop).

\begin{tabular}{|c|c|c|}
\hline Parameters & Description & Value \\
\hline$\Delta \phi_{c}$ & Phase Attenuation Required & $-14.78^{0}$ \\
\hline$\omega_{p}$ & $\begin{array}{c}\text { Bandwidth Corresponding to the Location } \\
\text { of Compensator's Pole }\end{array}$ & $2420.22 \mathrm{rad} / \mathrm{s}$ \\
\hline$\omega_{z}$ & $\begin{array}{c}\text { Bandwidth Corresponding to the Location } \\
\text { of Compensator's Zero }\end{array}$ & $4077.97 \mathrm{rad} / \mathrm{s}$ \\
\hline$\alpha$ & Constant Representing Ratio of $\omega_{z} \& \omega_{p}$ & 1.685 \\
\hline$G_{c o}$ & Compensator's Gain & 1.298 \\
\hline$T_{l a g}$ & Compensator's Time-Constant & $0.245 \times 10^{-3}$ \\
\hline
\end{tabular}

Transsfer function of the phase-lag compensator for OSC loop of the MSC control $G_{\text {lag.o }}(s)$ has obtained and expressed as,

$G_{\text {lag.o }}(s)=G_{c o}\left(\frac{s T_{\text {lag }}+1}{s \alpha T_{\text {lag }}+1}\right)=1.298\left(\frac{0.245 \times 10^{-3} \mathrm{~s}+1}{0.4128 \times 10^{-3} \mathrm{~s}+1}\right)$

Now, the OLTF of gain-lag compensated OSC loop of the MSC control $G_{o s c, M S C}^{o l, g l c}(s)$ is obtained as,

$G_{o s c, M S C}^{o l, g l c}(s)=\frac{0.001808 \mathrm{~s}^{2}+34.33 \mathrm{~s}+1.099 \times 10^{5}}{3.069 \times 10^{-15} \mathrm{~s}^{5}+1.013 \times 10^{-10} \mathrm{~s}^{4}+1.645 \times 10^{-6} \mathrm{~s}^{3}+0.01487 \mathrm{~s}^{2}+27.7 \mathrm{~s}}$

The PM and BW obtained from the bode diagram of gain-lag compensated are are $64.6^{0}$ and $3.14 \times 10^{3} \mathrm{rad} / \mathrm{s}$, respectively. Therefore, both PM and BW requirement are met. Actually, the phase-lag compensator shifts the phase curve down corresponding to the desired attenuation (around the desired BW). Bode diagram of both gain-compensated and gain-lag compensated systems are shown in Figure 7.

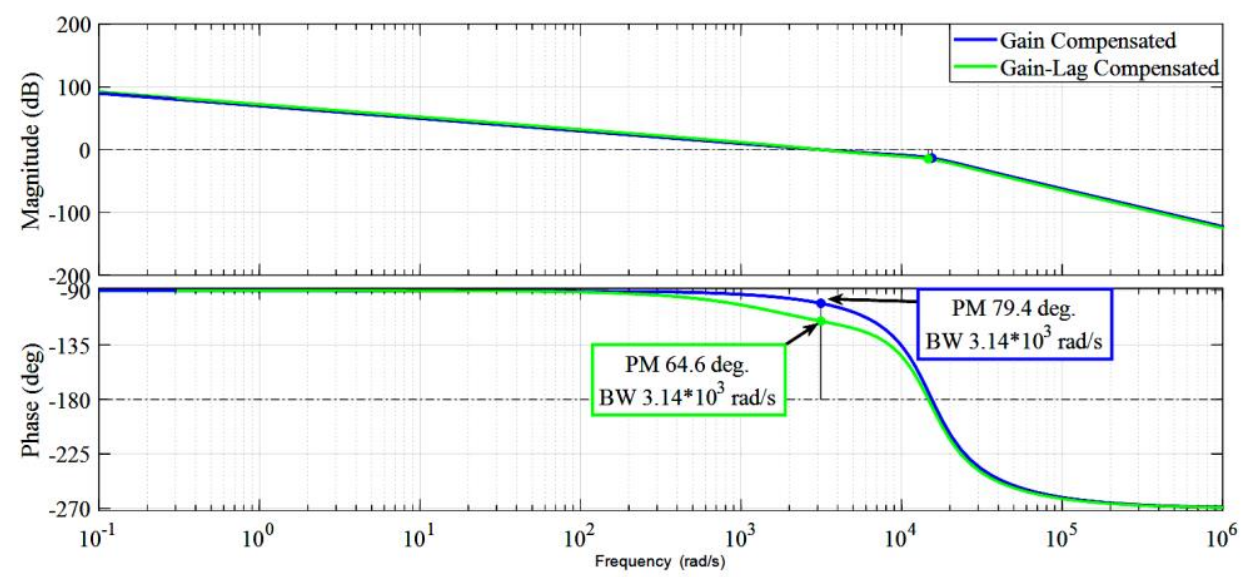

Figure 7. Bode diagram of gain compensated and gain-lag compensated OLTF of OSC-MSC. 
International Journal of Mathematical, Engineering and Management Sciences

Vol. 6, No. 2, 584-597, 2021

https://doi.org/10.33889/IJMEMS.2021.6.2.035

In order to observe the time-response of the system, step-responses of uncompensated, gain compensated and gain-lag compensated systems are obtained and system's performance parameters such as; maximum overshoot, rise time and settling time are noted. Figure 8 , shows these responses along with different performance indices.

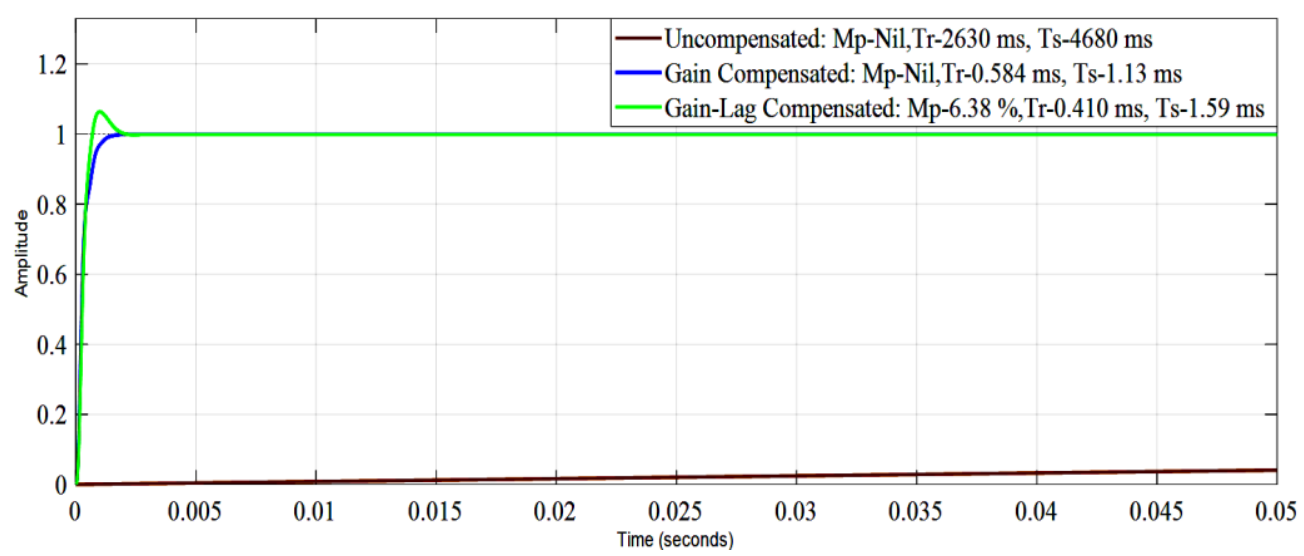

Figure 8. Time response of uncompensated, gain-compensated and gain-lag compensated systems.

Compensator's design specification, outcomes of frequency and time responces of uncompensated, gain-compensated and gain-lag compensated systems for both ICC and OSC loop are made available in Table 4.

Table 4. Design specifications and obseved performances.

\begin{tabular}{|c|c|c|c|c|c|c|c|c|c|c|}
\hline \multirow{6}{*}{$\begin{array}{c}\text { MACHINE SIDE } \\
\text { CONVERTER } \\
\text { CONTROL }\end{array}$} & \multicolumn{5}{|c|}{ Inner-Current-Control loop } & \multicolumn{5}{|c|}{ Outer-Speed-Control loop } \\
\hline & \multicolumn{5}{|c|}{ Design Specifications } & \multicolumn{5}{|c|}{ Design Specifications } \\
\hline & \multicolumn{2}{|c|}{ Frequency Response } & \multicolumn{3}{|c|}{ Time Response } & \multicolumn{2}{|c|}{ Frequency Response } & \multicolumn{3}{|c|}{ Time Response } \\
\hline & BW & PM & $\mathrm{M}_{\mathrm{p}}$ & $\mathrm{T}_{\mathrm{r}}$ & $\mathrm{T}_{\mathrm{s}}$ & BW & PM & $\mathrm{M}_{\mathrm{p}}$ & $\mathrm{T}_{\mathrm{r}}$ & $\mathrm{T}_{\mathrm{s}}$ \\
\hline & $(\mathrm{rad} / \mathrm{s})$ & (degree) & $(\%)$ & (ms) & (ms) & $(\mathrm{rad} / \mathrm{s})$ & (degree) & $(\%)$ & $(\mathrm{ms})$ & $(\mathrm{ms})$ \\
\hline & 12566.37 & 48.15 & 20 & 0.163 & 0.921 & 3141.59 & 64.62 & 5 & 0.683 & 1.88 \\
\hline \multirow{2}{*}{ System } & \multicolumn{5}{|c|}{ Observed Performance } & \multicolumn{5}{|c|}{ Observed Performance } \\
\hline & \multicolumn{2}{|c|}{ Frequency Response } & \multicolumn{3}{|c|}{ Time Response } & \multicolumn{2}{|c|}{ Frequency Response } & \multicolumn{3}{|c|}{ Time Response } \\
\hline Uncompensated & 635 & 88.2 & NIL & 3.34 & 6 & 0.835 & 90 & NIL & 2630 & 4680 \\
\hline Gain Compensated & 12600 & 57.9 & 10.6 & 0.105 & 0.343 & $3.14 * 10^{\wedge} 3$ & 79.4 & NIL & 0.584 & 1.13 \\
\hline $\begin{array}{c}\text { Gain-Lag } \\
\text { Compensated }\end{array}$ & 12600 & 48.1 & 20.3 & 0.101 & 0.546 & $3.14 * 10^{\wedge} 3$ & 64.6 & 6.38 & 0.410 & 1.59 \\
\hline
\end{tabular}

\section{Simulation Outcomes and Discussion}

Having designed the involved compensators for the system concern, a detailed simulation model of the PMSG based WECS is developed in MATLAB/Simulink environment, for evaluation of effectiveness of the design compensators. The WECS performance with such designed compensators has observed under different wind speed conditions. The test wind profiles used to evaluate the effectiveness of the designed compensators for different control loops and simulation outcomes are presented in Figure 9. WECS parameters are given in Appendix. 
International Journal of Mathematical, Engineering and Management Sciences

Vol. 6, No. 2, 584-597, 2021

https://doi.org/10.33889/IJMEMS.2021.6.2.035
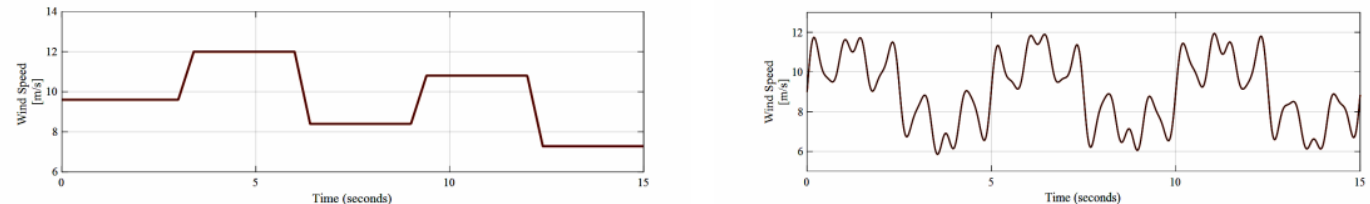

(a) Wind speed
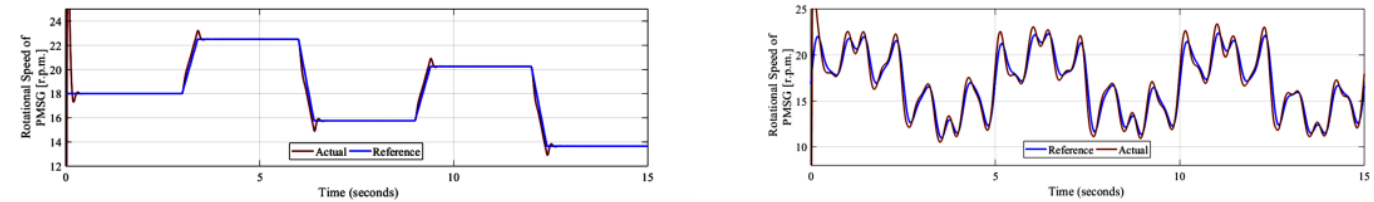

(b) Rotational speed of PMSG
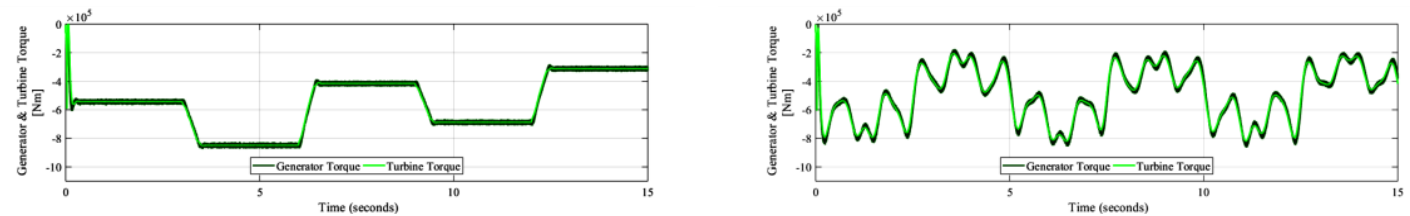

(c) Turbine's and PMSG's torque
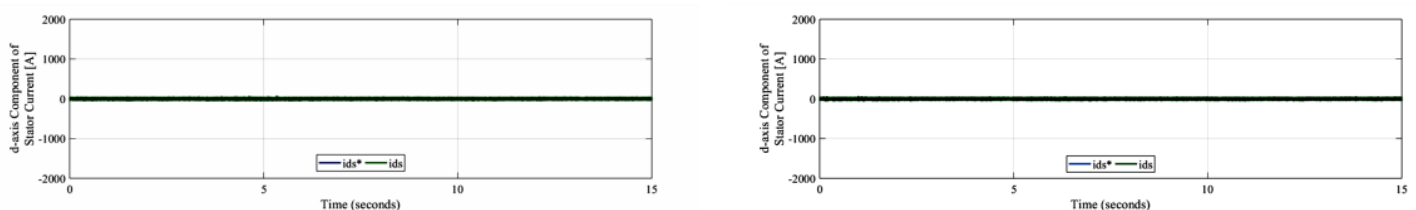

(d) d-axis component of stator current
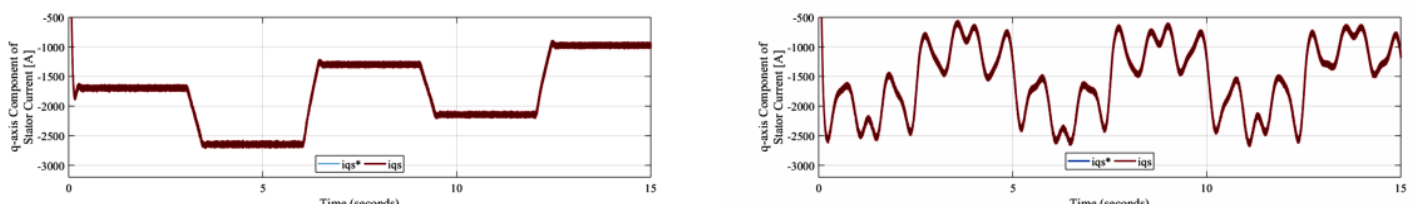

(e) q-axis component of stator current
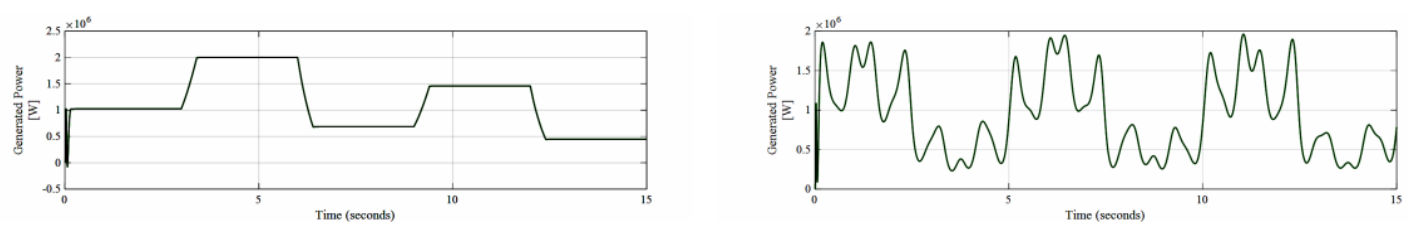

(f) Generated power
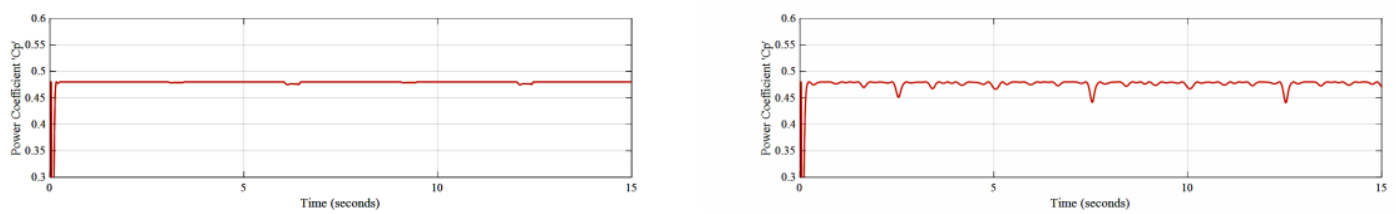

(g) Turbine's power coefficient

Figure 9. Performance of WECS under test wind profiles. 
International Journal of Mathematical, Engineering and Management Sciences

Vol. 6, No. 2, 584-597, 2021

https://doi.org/10.33889/IJMEMS.2021.6.2.035

Initial wind speed is considered $9.6 \mathrm{~m} / \mathrm{s}$ which drives the wind turbine at 18 r.p.m.. Turbine/generator torque, and average active power generatd are observed about $5.43 \mathrm{kNm}$ and $1.02 \mathrm{MW}$, respectively. After $3 \mathrm{~s}$, the wind speed gradually increases and settelled at $12 \mathrm{~m} / \mathrm{s}$, rotor speed is also found increasing accordingly and smmothly tracking the reference rotor speed corresponding to the MPPT. The rotor speed, turbine/generator torque, generated power corresponding to the wind speed of $12 \mathrm{~m} / \mathrm{s}$ are observed as 22.5 r.p.m., $8.48 \mathrm{kNm}$ and $2 \mathrm{MW}$, repectivelly. At $6 \mathrm{~s}$, the wind speed starts gradually decreasing to a value of $8.4 \mathrm{~m} / \mathrm{s}$, and the rotor speed is also found decreasing accordingly and smmothly tracking the reference rotor speed recursively calculated by MPPT algorithm. The rotor speed, turbine/generator torque, generated power corresponding to the wind speed of $8.4 \mathrm{~m} / \mathrm{s}$ are observed as 15.75 r.p.m., $4.15 \mathrm{kNm}$ and $0.68 \mathrm{MW}$, repectivelly. At $9 \mathrm{~s}$, the wind speed starts gradually increasing $\mathrm{g}$ and setteled to a value of $10.8 \mathrm{~m} / \mathrm{s}$, the rotor speed is also found increasing accordingly and smmothly tracking the reference rotor speed. The rotor speed, turbine/generator torque, generated power corresponding to the wind speed of $10.8 \mathrm{~m} / \mathrm{s}$ are observed as 20.25 r.p.m., $6.86 \mathrm{kNm}$ and $1.46 \mathrm{MW}$, repectivelly. At $12 \mathrm{~s}$, the wind speed starts gradually decreasing and setteled to a value of $7.2 \mathrm{~m} / \mathrm{s}$, the rotor speed is also found decreasing accordingly and smmothly tracking the reference rotor speed. The rotor speed, turbine/generator torque, generated power corresponding to the wind speed of 7.2 $\mathrm{m} / \mathrm{s}$ are observed as 13.5 r.p.m., $3.05 \mathrm{kNm}$ and $0.43 \mathrm{MW}$, repectivelly. Dependency of the torque on q-axis current can also be seen. From the curve of the power coefficient which is maintained at its reference i.e. at 0.48 demonstrates that MPPT operation has achived successfully, hense good compensator performance. The steady-state evaluation of different performance parameters of the turbine considered for the present study has carried out in our prior work (Srivastava et al., 2018).

The considered system is also subjected to a stochastically varying wind and the responses obtained are presented. Obtained responses demonstrates the effectiveness of the designed compensators aand achievement of MPPT successfully.

\section{Conclusions}

The research investigation presented in this paper is dedicated to present an alternative control solutions to renewable energy generation systems. In this study, phase-lag compensators has developed for both inner and outer loop of the machine-side-converter of a BTB-PWM-VSCs as an interface between PMSG based WTG and the grid. The designed compensators for inner and outer control loops of the R-FOC has used to control the generator current and rotor speed (to achieve MPPT). Compensators performance has evaluated through a detailed simulation of a PMSG base WECS in MATLAB/Simulink environment and promising responces has observed. The observed responses motivates for an extended work presenting the designing such compensators for grid-side-converter control of the aforementioned power electronic interface. Although, the compensator designing presented in this paper is for PMSG based system, the procdure discuused in the paper may attract the researchers in this field.

\footnotetext{
Appendix

PMSG Parameters: Nominal Power: 2MW, Nominal L-L Voltage: 690 V, Rated Rotor Speed: 22.5 rpm, No. of Pole Pairs: 26, Rated Mechanical Torque: 848.826 kNm, Maximum Flux Linkage: $5.8264 \mathrm{~Wb}$, Stator Winding Resistance: $0.821 \mathrm{mohm}$, dq-axis synchronous inductances: $1.5731 \mathrm{mH}$; Wind Turbine Parameters: Nominal Power: 2.0 MW, Nominal Rotational Speed: $22.5 \mathrm{rpm}$, Nominal Angular Speed: $2.356 \mathrm{rad} / \mathrm{s}$, Blade Radius: $41.25 \mathrm{~m}$, Air Density: $1.036 \mathrm{Kg} / \mathrm{m}^{3}$, Turbine Power Coefficient: 0.48 , TipSpeed-Ratio (TSR): 8.1; Grid Parameters: Grid Voltage: 690 V (L-L), 50 Hz.
} 
International Journal of Mathematical, Engineering and Management Sciences

Vol. 6, No. 2, 584-597, 2021

https://doi.org/10.33889/IJMEMS.2021.6.2.035

\section{Conflict of Intrest}

We confirm that there is no conflict of interest to declare for publication of this paper.

\section{Acknowledgement}

We would like to express our sincere thanks to the editor and anonymous reviewers for their time and valuable suggestions.

\section{References}

Baroudi, J.A., Dinavahi, V., \& Knight, A.M. (2007). A review of power converter topologies for wind generators. Renewable Energy, 32(14), 2369-2385.

Basilio, J.C., \& Matos, S.R. (2002). Design of PI and PID controllers with transient performance specification. IEEE Transactions on Education, 45(4), 364-370.

Chinchilla, M., Arnaltes, S., \& Burgos, J.C. (2006). Control of permanent-magnet generators applied to variable-speed wind-energy systems connected to the grid. IEEE Transactions on Energy Conversion, 21(1), 130-135.

Dahbi, A., Hachemi, M., Nait-Said, N., \& Nait-Said, M.S. (2014). Realization and control of a wind turbine connected to the grid by using PMSG. Energy Conversion and Management, 84, 346-353.

Freire, N., Estima, J., \& Cardoso, A. (2012).A comparative analysis of PMSG drives based on vector control and direct control techniques for wind turbine applications. Przeglad Elektrotechniczny, 88(1), 184-187.

Hamatwi, E., Davidson, I.E., \& Gitau, M.N. (2017). Rotor speed control of a direct-driven permanent magnet synchronous generator-based wind turbine using phase-lag compensators to optimize wind power extraction. Journal of Control Science and Engineering, 2017 Article ID 6375680.

Jain, B., Jain, S., \& Nema, R.K. (2015). Control strategies of grid interfaced wind energy conversion system: An overview. Renewable and Sustainable Energy Reviews, 47, 983-996.

Kim, K.H., Jeung, Y.C., Lee, D.C., \& Kim, H.G. (2012). LVRT scheme of PMSG wind power systems based on feedback linearization. IEEE Transactions on Power Electronics, 27(5), 2376-2384.

Kristiansson, B., \& Lennartson, B. (2006). Robust tuning of PI and PID controllers: using derivative action despite sensor noise. IEEE Control Systems Magazine, 26(1), 55-69.

Krohling, R.A., \& Rey, J.P. (2001). Design of optimal disturbance rejection PID controllers using genetic algorithms. IEEE Transactions on Evolutionary Computation, 5(1), 78-82.

Li, K. (2012). PID tuning for optimal closed-loop performance with specified gain and phase margins. IEEE Transactions on Control Systems Technology, 21(3), 1024-1030.

Mohseni, M., \& Islam, S.M. (2012). Review of international grid codes for wind power integration: Diversity, technology and a case for global standard. Renewable and Sustainable Energy Reviews, 16(6), 3876-3890.

Neath, M.J., Swain, A.K., Madawala, U.K., \& Thrimawithana, D.J. (2014). An optimal PID controller for a bidirectional inductive power transfer system using multiobjective genetic algorithm. IEEE Transactions on Power Electronics, 29(3), 1523-1531.

Ogata, K., \& Yang, Y. (2002). Modern control engineering. (Vol. 4). India: Prentice hall.

Polinder, H., Van Der Pijl, F.F.A., De Vilder, G.J., \& Tavner, P.J. (2006). Comparison of direct-drive and geared generator concepts for wind turbines. IEEE Transactions on Energy Conversion, 21(3), 725733 
International Journal of Mathematical, Engineering and Management Sciences

Vol. 6, No. 2, 584-597, 2021

https://doi.org/10.33889/IJMEMS.2021.6.2.035

Sharma, S., \& Singh, B. (2012). Control of permanent magnet synchronous generator-based stand-alone wind energy conversion system. IET Power Electronics, 5(8), 1519-1526.

Srivastava, P.K., Tiwari, A.N., \& Singh, S.N. (2018, November). Performance estimation of permanent magnet synchronous generator based wind energy conversion system. In 2018 5th IEEE Uttar Pradesh Section International Conference on Electrical, Electronics and Computer Engineering (UPCON) (pp. 1-7). IEEE. Gorakhpur, India.

Tiwari, R., \& Babu, N.R. (2016). Recent developments of control strategies for wind energy conversion system. Renewable and Sustainable Energy Reviews, 66, 268-285.

Tripathi, S.M., Tiwari, A.N., \& Singh, D. (2015). Grid-integrated permanent magnet synchronous generator based wind energy conversion systems: A technology review. Renewable and Sustainable Energy Reviews, 51, 1288-1305.

Tripathi, S.M., Tiwari, A.N., \& Singh, D. (2016). Optimum design of proportional-integral controllers in grid-integrated PMSG-based wind energy conversion system. International Transactions on Electrical Energy Systems, 26(5), 1006-1031.

Wang, W., Chen, N., Zhu, L.Z., \& Xu, D.G. (2009, April). Phase angle compensation control strategy for low voltage ride through of doubly-fed induction generator. In 2009 International Conference on Sustainable Power Generation and Supply (pp. 1-7). IEEE. Nanjing, China.

Wu, B., Lang, Y., Zargari, N., \& Kouro, S. (2011). Power conversion and control of wind energy systems (Vol. 76). John Wiley \& Sons, Inc., Hoboken, New Jersey.

Yaramasu, V., Wu, B., Sen, P.C., Kouro, S., \& Narimani, M. (2015). High-power wind energy conversion systems: State-of-the-art and emerging technologies. Proceedings of the IEEE, 103(5), 740-788.

Yaramasu, V., Dekka, A., Durán, M.J., Kouro, S., \& Wu, B. (2017). PMSG-based wind energy conversion systems: survey on power converters and controls. IET Electric Power Applications, 11(6), 956-968.

Zigmund, B., Terlizzi, A.A., Garcia, X.D.T., Pavlanin, R., \& Salvatore, L. (2011). Experimental evaluation of PI tuning techniques for field oriented control of permanent magnet synchronous motors. Advances in Electrical and Electronic Engineering, 5(1), 114-119. 